\title{
Quasistatic Seismic Damage Indicators for RC Structures from Dissipating Energies in Tangential Subspaces
}

\author{
Wilfried B. Krätzig ${ }^{1,2}$ and Yuri S. Petryna ${ }^{3}$ \\ ${ }^{1}$ Institute for Statics \& Dynamics, Ruhr-University Bochum, 44780 Bochum, Germany \\ ${ }^{2}$ Kraetzig \& Partners Engineering Consultants, Buscheyplatz 9-13, 44801 Bochum, Germany \\ ${ }^{3}$ Technical University of Berlin, Gustav-Meyer-Allee 25, 13355 Berlin, Germany
}

Correspondence should be addressed to Yuri S. Petryna; yuriy.petryna@tu-berlin.de

Received 4 September 2013; Accepted 29 September 2013; Published 12 January 2014

Academic Editor: Anaxagoras Elenas

Copyright (C) 2014 W. B. Krätzig and Y. S. Petryna. This is an open access article distributed under the Creative Commons Attribution License, which permits unrestricted use, distribution, and reproduction in any medium, provided the original work is properly cited.

\begin{abstract}
This paper applies recent research on structural damage description to earthquake-resistant design concepts. Based on the primary design aim of life safety, this work adopts the necessity of additional protection aims for property, installation, and equipment. This requires the definition of damage indicators, which are able to quantify the arising structural damage. As in present design, it applies nonlinear quasistatic (pushover) concepts due to code provisions as simplified dynamic design tools. Substituting so nonlinear time-history analyses, seismic low-cycle fatigue of RC structures is approximated in similar manner. The treatment will be embedded into a finite element environment, and the tangential stiffness matrix $\mathbf{K}_{T}$ in tangential subspaces then is identified as the most general entry for structural damage information. Its spectra of eigenvalues $\lambda_{i}$ or natural frequencies $\omega_{i}$ of the structure serve to derive damage indicators $D_{i}$, applicable to quasistatic evaluation of seismic damage. Because det $\mathbf{K}_{T}=0$ denotes structural failure, such damage indicators range from virgin situation $D_{i}=0$ to failure $D_{i}=1$ and thus correspond with Fema proposals on performance-based seismic design. Finally, the developed concept is checked by reanalyses of two experimentally investigated RC frames.
\end{abstract}

\section{Introduction}

The remarkable reduction of life losses in seismic events over the last 75 years is clearly a merit of the enormous increase in research on structural seismic safety. Consequently, due to improvements of earthquake-resistant design concepts and of modern seismic codes, for example, EC 8 [1], earthquakes with thousands of fatalities until far into the 20th century demand nowadays only few ones. But while in several strong earthquakes (San Fernando 1971, Imperial Valley 1979, Loma Prieta 1989, Northridge 1994, Tohoku 2011) life losses remained limited, material losses raised dramatically with each event. This trend cries for new seismic design concepts beyond life protection, namely, a better control of earthquake damage along the structures' paths to seismic failure. This requires a more intensive emphasis on structural seismic damage, which by experience correlates with material losses from installations and equipment.
Structural safety concepts compare actions $S$ on a particular structure with its resistance $R$, generally for codeprescribed limit states. Structural failure is then defined as

$$
\text { failure }=\{f\}:=\{R \leq S\} .
$$

Code standards transform (1) into limit state conditions $g(\mathbf{X})$ for state vectors $\mathbf{X}$, the latter as functions of the design variables $\mathbf{X}_{d}$ :

$$
\begin{aligned}
g(\mathbf{X})=\left(\gamma_{R}\right)^{-1} R(\mathbf{X})-\gamma_{S} \times S(\mathbf{X}) & \leq 0 & & \text { for failure, } \\
& >0 & & \text { for survival, }
\end{aligned}
$$

in which the partial safety factors $\gamma_{S}$ of the actions $S$ and $\gamma_{R}$ of the resistance $R$ are due to national code regulations. Obviously, (2) formulates structural safety by virtue of force variables at failure point, a customary manner in structural engineering. 
Such design concepts are also code prescribed in case of seismic failure. But the explained extension of seismic design aims requires a turn towards structural damage, wherein the seismic damage formation-not force resistance $R$ - has to be prosecuted, until limited by final damage bounds. Consequently, such more advanced protection aims like reduction of material losses must be combined with the basic safety objective of human life protection, which can be done within techniques of performance-based seismic design [2].

Codified seismic design concepts [1] are generally based on (linear elastic) response spectra. Codes favor the use of quasistatic analyses instead of full time histories, corresponding well with quasistatic constitutive laws [3] from monotonic material tests. If linear elastic structural models are applied, the evaluation of damage is impossible, since design formats (2) are tailored towards force-limitations [4]. It is a usual design practice. Inclusion of damage always requires consideration of material nonlinearity. The simplest quasistatic seismic simulation technique then uses nonlinear pushover analyses.

On the other hand, seismic loading creates low-cycle fatigue processes in the materials involved, which after 20 to 1000 sufficiently intensive load cycles will lead to seismic failure. Those damage paths to failure can be marked by damage indicators [5], generally in dynamic settings. But in structural earthquake-resistant design practice, time-history computations-especially with time-dependent material laws-are very rare. So this paper addresses the question whether realistic estimates for such time-dependent structural damage evolutions can be approximated by nonlinear quasistatic damage evaluation.

To approach these aims, the paper will be based on damage-controlled limit states as proposed in performancebased seismic engineering concepts [2]. It then depicts pushover analyses, followed by description and time-invariant approximation of low-cycle (RC) fatigue processes, justifying a quasistatic treatment. The work will close with necessary steps for quasistatic seismic damage evaluation, followed by two applications.

\section{Extended Seismic Protection Based on Damage Indicators}

Losses in strong seismic events, human as well as material ones, depend on the seismically dismissed energy, the area's population density, the degree of economic development, and the level of earthquake-resistant safety provisions. Buildings have been primarily designed for protection of human lives, but we will also be aware of material losses. As a consequence of this, not only one seismic event (of 475 years of return period) should be considered, but also the building's functionality has to be differentiated.

Figure 1 elucidates this idea in the well-known concept of the Federal Emergency Management Agency (Fema) [2] and of the Structural Engineers Association of California (SEAOC) [6]. Such performance-based seismic design concept centers the attention towards the quantification of seismic damage in the design, assuming the latter to be correlated

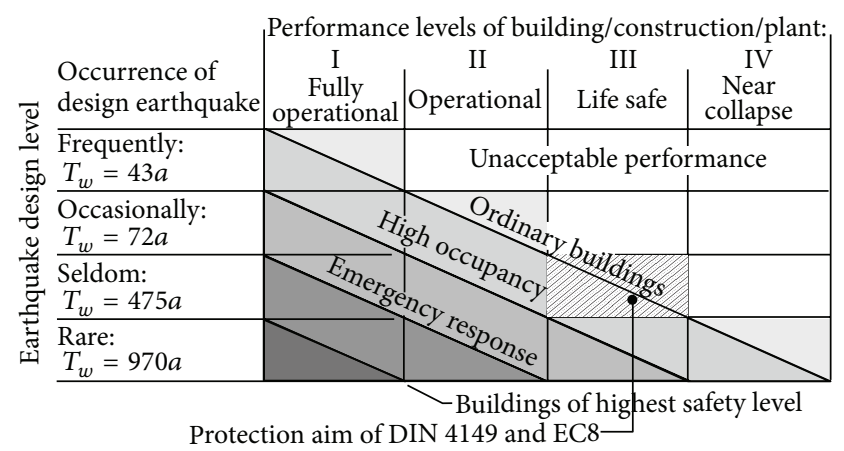

FIGURE 1: Recommended performance objectives for buildings [2].

TABLe 1: Limit states and damage levels according to Fema 273.

\begin{tabular}{lccc}
\hline & Structural limit states & Damage levels & Damage indices \\
\hline ND No damage, virgin structure & 0 & 0.00 \\
IO & Immediate occupancy & I & 0.05 \\
ID & Incipient damage & & 0.10 \\
LS & Life safety threatens & II & $0.20 / 0.25$ \\
CP & Collapse prevention & III & $0.40 / 0.50$ \\
IC & Incipient collapse & IV & $>0.90$ \\
\hline
\end{tabular}

with material losses of installation and equipment. This basic assumption of seismic damage correlation avoids modeling of each installation/equipment element as attached structural component in the computational model, but it remains an empirical working hypothesis requiring the determination of the generated seismic structural damage.

Figure 1 proposes in this sense different protection aims of buildings in the columns, and seismic events of increasing intensities in the rows, measured in return periods $T_{w}[1]$. In the diagonal, classes of structures are distinguished with different design damages/vulnerabilities for various seismic events. Table 1 explains the damage states in more detail, introducing damage levels as follows [2].

(i) Level 0: no damage, virgin structure.

(ii) Level I: very limited structural damage, no risk of lifethreatening injury.

(iii) Level II: significant damage, low risk of lifethreatening injury.

(iv) Level III: substantial damage, significant risk of injury from falling hazards.

(v) Level IV: collapse is imminent, highest risk of life to occupants.

FEMA documents, for example, $[2,6]$, order numerical values to these damage levels; they also propose a normalization from 0.00 (virgin) to 1.00 (seismic failure). But the interesting fact is that no advice is given by FEMA, which of the existing damage indicators is preferred.

In the literature there exist a great variety of damage indices, as can be seen from the survey in [5]. Most indicators describe damage in local cross-sections; thus they are unsuited for damage description of complete structures. 
But most important: All indices are rather empirical, and none of them has a sound foundation from mathematics or structural mechanics, as we see on the hybrid PARK-ANG index [7], which combines dissipated energies with inelastic story drifts:

$$
D=\frac{\delta_{m}}{\delta_{f}}+\beta \frac{E_{r}}{F_{y} \delta_{f}} .
$$

Herein $\delta_{m}\left(\delta_{f}\right)$ denotes the maximum occurring (bearable) structural displacement. $E_{r}$ is the total dissipated energy, $F_{y}$ the structural yield resistance, and $\beta$ a parameter to be determined by tests [7]. The combination of dissipated energies and story drifts in (3) is really too empirical to be applied in a theoretical sound earthquake-resistant design concepts.

In Section 6 we will derive a set of damage indices $D_{i}, i=$ $1, \ldots, n$, from inherent mechanical properties of a particular structure's path to seismic failure. These parameters will have the following main properties serving as an optimal basis for earthquake-resistant designs.

(i) They will be related to the entire structure.

(ii) They will describe the seismic low-cycle process with a sufficient accuracy from the mechanical viewpoint.

(iii) They will be based on mechanics, for example, the structural state variables of the seismic process.

(iv) They will range from 0.00 (undamaged virgin state) to 1.00 (failure).

The authors have certain experiences with indices $D_{i}$ for damage problems other than seismic ones. The have found that values around 0.6 separate economically structural repairs from reconstruction. This holds especially for RC structures, on which we will now concentrate.

\section{Quasistatic Nonlinear Simulation}

For application in present anti-seismic design concepts, the further treatment will be quasistatic. Then for monotonic deformation processes of materially nonlinear responding structures, tangential subspace simulations up to failure are well-established tools in present engineering. Because of material degradation of the structural resistance $R$ during earthquakes, seismic damage simulations are nonlinear processes. To derive their governing response equations we imbed the treatment for arbitrary structures into a FEenvironment, in which the nodal degrees of freedom are arranged in the $m$-dimensional vector field

$$
\mathbf{V}=\left\{\begin{array}{llllll}
V_{1} & V_{2} & \cdots & V_{i} & \cdots & V_{m}
\end{array}\right\},
$$

and the nodal forces, in dual order to $\mathbf{V}$, in

$$
\mathbf{P}=\left\{\begin{array}{llllll}
P_{1} & P_{2} & \cdots & P_{i} & \cdots & P_{m}
\end{array}\right\} .
$$

In this frame the structural response is governed by the following nonlinear stiffness equation, with $\mathbf{G}$ as the vector functional of the structural resistance $R$ :

$$
\mathbf{G}(\mathbf{V}, \mathbf{d})=\mathbf{P} .
$$

This $m$-dimensional set of nonlinear algebraic equations describes equilibrium/compatibility in terms of the internal resistance $\mathbf{G}$-with inelastic deformation $(\mathbf{V})$ and damaging (d) material model properties-due to an external force process P. All nonlinear structural properties, anchored generally in the constitutive laws on Gauss point level (see Figure 2), are assumed to be fixed in required quality in G.

To derive the basis for incremental-iterative solution strategies from (6), we decompose the external nodal kinematics $\mathbf{V}$ and loads $\mathbf{P}$ of a certain structural state into variables $\overline{\mathbf{V}}, \overline{\mathbf{P}}$ of a known fundamental state and their unknown increments $\delta \mathbf{V}, \delta \mathbf{P}$, reaching from fundamental to neighboring position:

$$
\mathbf{V}=\overline{\mathbf{V}}+\delta \mathbf{V}, \quad \mathbf{P}=\overline{\mathbf{P}}+\delta \mathbf{P} .
$$

Assuming now all increments as infinitesimally small variations, we gain from the first variation of (6) with respect to the fundamental state $\overline{\mathbf{V}}, \overline{\mathbf{P}}$ the $m$-dimensional set of algebraic equation for the increments $\delta \mathbf{V}, \delta \mathbf{P}$; namely,

$$
\left.\frac{\partial \mathbf{G}}{\partial \mathbf{V}}\right|_{\overline{\mathbf{V}}} \cdot \delta \mathbf{V}=\delta \mathbf{P}
$$

Substituting herein for the load variation $\delta \mathbf{P}=\mathbf{P}-\overline{\mathbf{P}}$, then for $\overline{\mathbf{P}}$ the left-hand side of the original stiffness relation (6), we receive the tangential stiffness equation, which forms the basis of finally applied iterative solution techniques:

$$
\mathbf{K}_{T}(\overline{\mathbf{V}}, \overline{\mathbf{d}}) \cdot \delta \mathbf{V}=\delta \mathbf{P}=\mathbf{P}-\mathbf{F}_{I}(\overline{\mathbf{V}}, \overline{\mathbf{d}}),
$$

with the vector $\delta \mathbf{V}$ of the increments of the global degrees of freedom, and

$$
\begin{gathered}
\mathbf{K}_{T}=\left.\frac{\partial \mathbf{G}}{\partial \mathbf{V}}\right|_{\overline{\mathbf{V}}} \text { the tangential stiffness matrix, } \\
\mathbf{F}_{I}=\mathbf{G}(\overline{\mathbf{V}}, \overline{\mathbf{d}}) \quad \text { the internal equilibrium force vector. }
\end{gathered}
$$

Since $\mathbf{K}_{T}$ and $\mathbf{F}_{I}$ depend on the reached deformation $\overline{\mathbf{V}}$, the tangential stiffness equation requires iterative solution techniques for the increments $\delta \mathbf{V}$. In (9), $\mathbf{P}$ represents the total applied load at a certain solution point, and $\mathbf{d}$ stands for the structural damage, later on detected as function of $\mathbf{K}_{T}$.

Materially nonlinear structural analyses, here applied as pushover analyses, can be carried out on rather different levels of mechanical exactness and complexity: beams with plastic hinges, with or without stiffness iterations, are the least complex alternative; nonlinear multilevel (multiscale) simulations form the other extreme [8]. Thus different model complexity may influence the simulation accuracy of (9) and so the later seismic damage detection.

In order to detail (macroscopic) materially nonlinear structural FE simulations [8], we return to a multilevel (multi-scale) simulation concept as the most complex analysis scheme and distinguish the following four simulation levels due to Figure 2.

(i) The first one is the structural level, on which all variables of the tangential stiffness relation (9) are defined. 


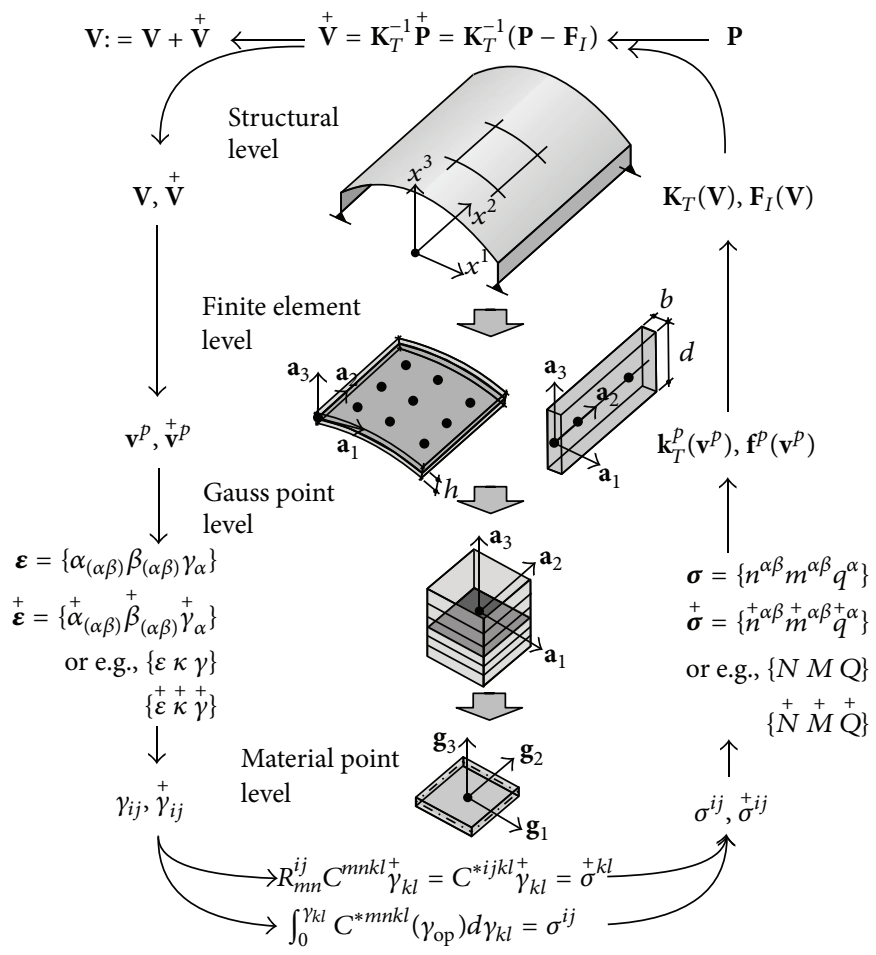

FIGURE 2: Variables and analysis scheme of multilevel simulation technique.

(ii) The second one is the level of classical FEs (beams, plates, and shells), connected with the previous one by kinematic relations in the nodal points.

(iii) In the third level, with regard to materially nonlinear actions and damage phenomena, the applied FEssee Figure 2-are equipped in their Gauss points with a layered structure, such that each FE-GAuss point consists of a chain of integration subpoints, one in each layer.

(iv) Finally, at these subpoints on material level, the constitutive relations including their nonlinear properties and failure bounds are defined.

The material point level is generally the lowest macroscopic simulation level in design practice. It collects all material information usually in a 3D $\left(x^{i}: x^{1}, x^{2}, x^{3}\right)$ or $2 \mathrm{D}$ $\left(x^{\alpha}: x^{1}, x^{2}\right)$ simulation space. Here suitable constitutive laws of the material components have to be activated [9], for incorporation in $\mathbf{K}_{T}$ and $\mathbf{F}_{I}$. Applying beam, plate, or shell elements, engineering simplifications for constitutive laws and failure conditions are often in favor, particularly for design purposes (see Section 8).

\section{Nonlinear Pushover Analyses}

We now return to seismic problems, that means to problems of nonlinear dynamics, if the structure's path until seismic failure will be investigated. Instead of attempting to solve the original nonlinear equation of motion

$$
\mathbf{M} \cdot \ddot{\mathbf{V}}+\mathbf{G}(\dot{\mathbf{V}}, \mathbf{V}, \mathbf{d})=\mathbf{P}(t),
$$

we concentrate for a short moment on the tangential subspace to $\{\ddot{\mathbf{V}}, \dot{\mathbf{V}}, \mathbf{V}, \mathbf{P}\}$ and thus on the incremental tangential equation of motion:

$$
\mathbf{M} \cdot \delta \ddot{\mathbf{V}}+\mathbf{C}_{T} \cdot \delta \dot{\mathbf{V}}+\mathbf{K}_{T} \cdot \delta \mathbf{V}=\mathbf{P}(t)-\mathbf{F}_{I}(t) .
$$

The derivation of (13) from the original nonlinear equation of motion (12) can be found in detail in [10]. In (13), the vectors $\{\delta \ddot{\mathbf{V}}, \delta \dot{\mathbf{V}}, \delta \mathbf{V}\}$ represent increments of the nodal equivalents, namely, accelerations, velocities, and deformation degrees of freedom. As a nonlinear differential equation in time $t$, (13) would require time-history solution for an (spectrumcompatible) acceleration functions $a(t)$, with stiffness iterations in each time step.

In the present structural design practice, such complex nonlinear time-history verifications are completely unusual. National seismic codes generally require linear dynamic analyses, if time-history simulations are selected; mostly linear quasistatic formats are applied. Pushover analyses serve since 30 years as approximate quasistatic but nonlinear substitution.

Pushover analyses $[4,11]$ are based on standardized design spectra of the respective site [12], generally prescribed in the respective code, and on dynamic structural properties, namely, mode shapes as well as natural frequencies of 
the undamaged structure. A pushover analysis consists of the following essential steps [13].

(i) We select a (code-given) design spectrum of seismic accelerations for the building site.

(ii) The considered structure is represented by a suitable FE discretization, and all (nonlinear) material properties on suitable structural levels (Figure 2) are specified.

(iii) Execution of an eigenvalue analysis of the undamaged linear-elastic structural model to receive critical natural frequencies (or periods) and corresponding mode shapes. From them follow the modal participation factors, which form the seismic load bases for each mode shape in each structural point.

(iv) With all these information the design spectrum delivers maximum seismic modal excitation loads and maximum modal pseudodeformations.

(v) Both groups of variables are then united by modal superposition, if different mode shapes participate in the seismic response.

(vi) These superposed seismic nodal loads are applied in incremental manner on the structure for a quasistatic nonlinear simulation process, the pushover analysis. It stops after all seismic loads are applied, the structural model fails, or the deformation limit has been reached. The gained stress resultants then are the basis of the seismic design, as detailed in $[12,14]$.

In summary, pushover verifications are nonlinear quasistatic approximations of a highly nonlinear dynamic loading process. So one can never expect exact correspondence of their solutions compared to those ones of nonlinear timehistory analyses. But from comparable simulations in the literature it seems to hold true that pushover analyses deliver mostly some upper bounds of the internal forces, not far away from physical reality. In engineering design practice these strong deficiencies of pushover concepts, mainly the incognizance of the true alternating seismic actions towards failure [11], and the ignorance of the structural stiffness weakening are allowed, if nonlinearity will be taken into account in a simple manner.

All values of dynamic structural stiffness used in this approximate analysis stem from the undamaged (virgin) structure. The fact that they will decrease during the seismic damage process and may finally end up with those ones of the deadly injured structure may confirm the suspicion that the pushover concept delivers upper bounds of the design variables, since generally inelastic mechanisms reduce the design forces $[4,15]$.

In spite of all these deficiencies, pushover analyses will be considered as the background of this present work for time-independent seismic damage evaluation and to estimate seismic vulnerabilities of structures under design. Before detailing this we will now have a look into low-cycle fatigue processes to also find for them a quasistatic approximation.

\section{Quasistatic Damage Approximation of Low-Cycle Fatigue}

Seismic failure of RC structures or their components follows a low-cycle fatigue process, in which after 20-100 stressstrain alternations of sufficient intensity cross-sections will fail. In modern research, such fatigue processes are treated as complex phenomena on mesoscale with detailed description of crack-formation, crack-closing, bond-slip, and internal stress redistribution. In the design of structures, empirical macroscopic models for low-cycle fatigue failure are applied; the most modern ones are based on dissipated energies, whereby close correspondence to monotonic failure of RC specimen is aspired $[16,17]$.

Some energetic contribution has been modeled also in the second contribution of the PARK-ANG indicator (3), in an extremely simplified and unsatisfying manner. Accepting the properties of damage indices from Section 2, a much better damage description is the $D_{Q}$-index introduced in [17]. This indicator consists solely of dissipated energies of cyclic deformations, up to failure. $D_{\mathrm{Q}}$ has a sound theoretical (macroscopic) basis and has been tested extensively in largescale experiments [17] on beams, columns, and beam-column connections. Bending as well as normal and shear force failure has been considered. For cyclic failure on one side of a particular cross-section, the $D_{\mathrm{Q}}$-index distinguishes primary half cycles (energies of new deformation amplitudes) and secondary half cycles (energies of redeformation amplitudes) of the cyclic damage process, a distinction discovered by [18]. For all further $D_{Q}$-details the reader is referred to $[5,17]$.

In the following, we present a brief explanation for a cross-section with double reinforcement under cyclic bending. In the moment-curvature $(M-\kappa)$ plane, as explained in Figure 3, two damage contributions $D_{Q}^{+}$for positive deformation and $D_{\mathrm{Q}}^{-}$for negative deformation are defined as

$$
D_{\mathrm{Q}}^{+}=\frac{E_{P}^{+}+E_{S}^{+}}{E_{M}^{+}+E_{S}^{+}}, \quad D_{\mathrm{Q}}^{-}=\frac{E_{P}^{-}+E_{S}^{-}}{E_{M}^{-}+E_{S}^{-}},
$$

with $E_{P}^{+}$as complete dissipated energies of all primary half cycles, $E_{S}^{+}$as complete dissipated energies of all secondary half cycles, and $E_{M}^{+}$as dissipated failure energy for monotonic deformation, all for positive deformation. The minus sign in (14) holds for negative deformation (reverse deformation cycles). From these constituents, the final $D_{Q}$-indicator is defined as follows:

$$
D_{\mathrm{Q}}=D_{\mathrm{Q}}^{+}+D_{\mathrm{Q}}^{-}+D_{\mathrm{Q}}^{+} * D_{\mathrm{Q}}^{-}
$$

This indicator can be formed successively during numerical time-step integration or from recorded dynamic test data. As observed from (14) and (15), $D_{Q}$ is scaled such that the virgin situation starts with $D_{Q}=0$, and failure is designated for $D_{\mathrm{Q}}=1$. Figures 4 and 5 demonstrate these properties by a recalculation of an elderly beam experiment from Berkeley [5].

In quasistatic approximations, for example, pushover analyses, all time-history integrations have to be avoided. So 


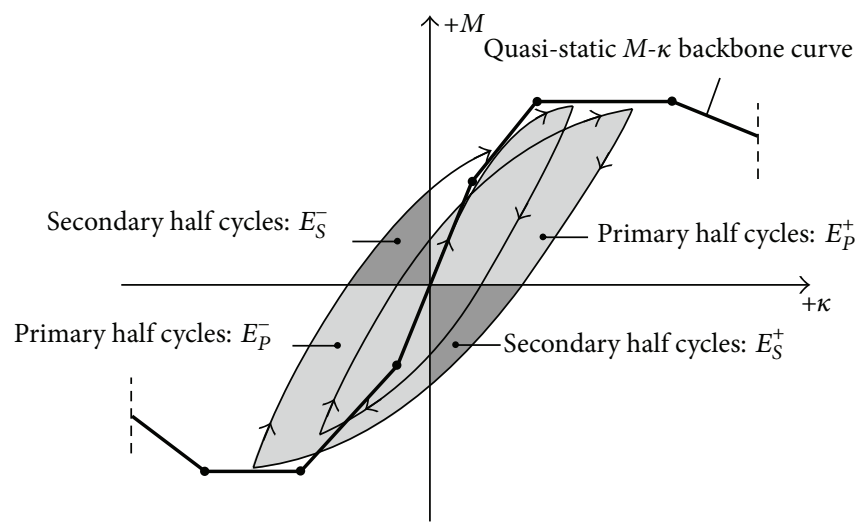

FIGURE 3: Cyclic deformation and dissipated energies.

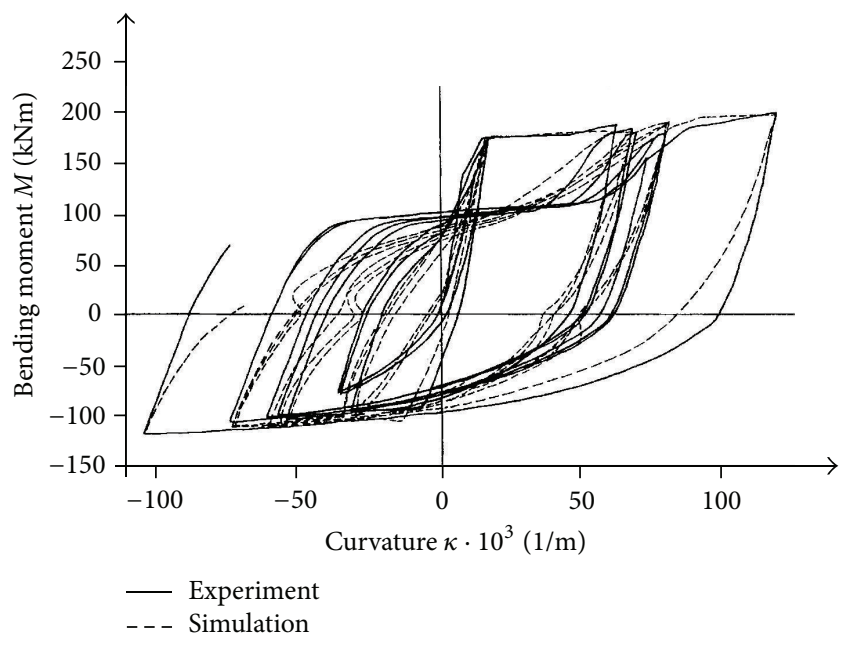

FIGURE 4: Moment-curvature relation of a cyclically loaded test beam.

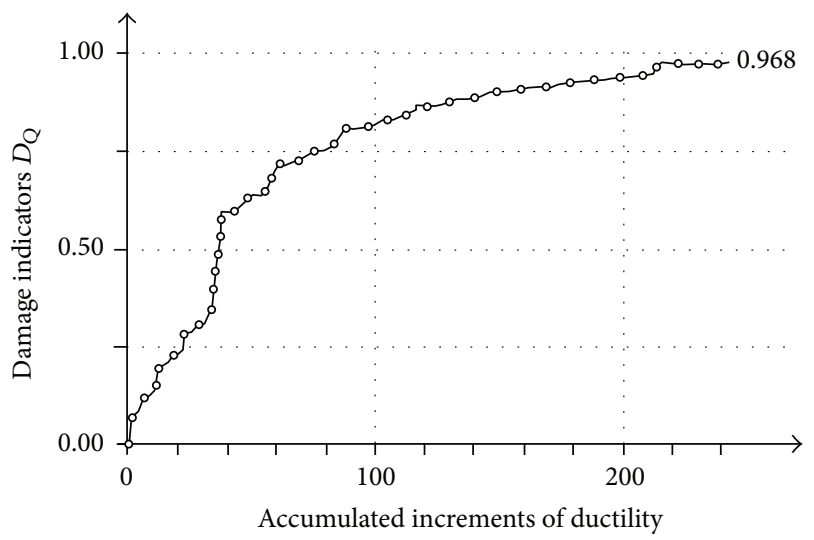

FIgURE 5: $D_{\mathrm{Q}}$-damage evolution corresponding to Figure 4 .

still for one single cross-section we set up the question if $D_{Q}$ can be approximated by a monotonic deformation process, only using the backbone curve and its monotonic failure energy? For proof, we transform one of the parameters from (14) into an infinite TAYLOR-series:

$$
D_{\mathrm{Q}}^{+}=\frac{E_{P}^{+}}{E_{M}^{+}}+\frac{E_{S}^{+}}{E_{M}^{+}}\left(1-\frac{E_{P}^{+}}{E_{M}^{+}}\right)-\left(\frac{E_{S}^{+}}{E_{M}^{+}}\right)^{2}\left(1-\frac{E_{P}^{+}}{E_{M}^{+}}\right)^{2}+\cdots
$$

We observe thereby that the normalized monotonic energies $E_{P}^{+} / E_{M}^{+}$, determinable just from quasistatic analyses, form the first and dominant terms in $D_{\mathrm{Q}}$, respectively. All the following energy contributions in (16) obviously can be considered as correction terms of higher order.

We now transform this recognition to complete structures. For design purposes, we are primarily interested in the maximum seismic damage. The upper limit $D_{Q}^{+}=1$ of (16) is formed for $E_{P}^{+} \Rightarrow E_{M}^{+}$, so a quasistatic failure analysis seems well applicable to determine the upper limits of contributing sectional damage. Consequently, estimation of structural damage from pushover concepts can be transferred as an upper limit estimate to the entire structures.

\section{Time-Invariant Approximation of Seismic Damage}

During a seismic event of sufficient intensity, RC structures will be weakened by inelastic actions and eventually fail. This degradation process can be monitored as a successive stiffness reduction of the structural resistance $R$, reflected in the vector functional $\mathbf{G}$ (6). Since structural damage $\mathbf{d}$ depends also on the forming inelastic deformation, the tangential stiffness matrix $\mathbf{K}_{T}$ (10) is considered as the most suitable entry for damage description $[19,20]$.

The damage measures, later defined in (18), had been derived mainly for deterioration and life-duration problems of structures, in which the time scale is enlarged compared to physical time $t$, such that quasistatic treatment is justified. Using time-independent pushover analyses as approximation of nonlinear structural seismic processes, time is completely deleted, such that quasistatic damage description is the only alternative.

How is $\mathbf{K}_{T}$ connected with structural softening and failure? Figure 6 repeats the basic fact that for integer structures 
Definition: structural integrity is defined by stable equilibrium paths (for simplicity, structural instabilities are excluded)

$$
\left[\mathbf{K}_{T}\right] \cdot[\stackrel{+}{\mathbf{V}}]=[\mathbf{P}]-\left[\mathbf{F}_{\mathbf{i}}\right] \longrightarrow[\stackrel{+}{\mathbf{V}}]=\left[\mathbf{K}_{T}^{-1}\right] \cdot\left([\mathbf{P}]-\left[\mathbf{F}_{\mathbf{i}}\right]\right)
$$

Prerequisites for structural integrity:

$\mathbf{K}_{T}$ : nonsingular $\operatorname{det} \mathbf{K}_{T} \neq 0$

positive definite $\stackrel{+}{\mathbf{V}}^{T} \cdot \mathbf{K}_{T} \cdot \stackrel{+}{\mathbf{V}}>0$

all eigenvalues $\lambda_{i}>0,1 \leq i \leq m$

FIgURE 6: Conditions for structural integrity.

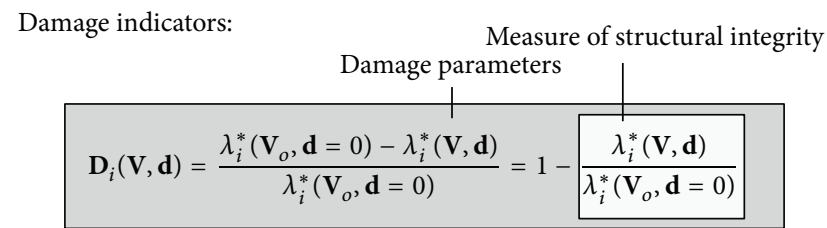

$\lambda_{i}^{*}$ : eigenvalues $\lambda_{i}, 1 \leq i \leq m$, of $\mathbf{K}_{T}(\mathbf{V}, \mathbf{d})$ :

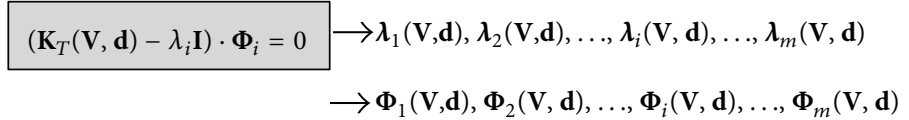

The corresponding eigenvectors $\boldsymbol{\Phi}_{i}, 1 \leq i \leq m$, map the damage

formation on the external deformations

FIgURE 7: Definition of damage indicators.

$\mathbf{K}_{T}$ is regular and positive definite; thus all its (hypothetically) transformed main diagonal elements are positive. In case of structural failure, $\mathbf{K}_{T}$ gets singular, det $\mathbf{K}_{T}=0$ and thus at least one main diagonal stiffness element vanishes. So $\mathbf{K}_{T}$ accompanies all quasistatic structural responses, also timeindependently approximated seismic ones, from structural birth until final failure [9, 19-21].

Since $\mathbf{K}_{T}$ (generally) is quadratic and symmetric, it can be transformed into a diagonal form, with the eigenvalues $\lambda_{i}$, $i=1,2, \ldots, m$, as principal stiffness elements

$$
\overline{\mathbf{K}}_{T}=\operatorname{diag}\left\{\begin{array}{llllll}
\lambda_{1} & \lambda_{2} & \cdots & \lambda_{i} & \cdots & \lambda_{m}
\end{array}\right\} .
$$

The diagonal matrix (17) can be used to form sets of damage indicators $D_{i}, i=1,2, \ldots, m$, as repeated in detail in Figure 7:

$$
D_{i}=\frac{\lambda_{i}\left(\mathbf{V}_{0}, \mathbf{d}=0\right)-\lambda_{i}(\mathbf{V}, \mathbf{d})}{\lambda_{i}\left(\mathbf{V}_{0}, \mathbf{d}=0\right)}=1-\frac{\lambda_{i}(\mathbf{V}, \mathbf{d})}{\lambda_{i}\left(\mathbf{V}_{0}, \mathbf{d}=0\right)}
$$

From this definition we observe that the elements of $D_{i}$ take values between $D_{i}=0$ for the undamaged state and $D_{i}=$ 1 for the failure state. Obviously, these damage indicators are able to denote properly all additional limit states from Table 1. Further, they have been gained as inherent structural mechanics properties of a considered structure, controlled by its nonlinear quasistatic seismic response path. Obviously, the $D_{i}$ have a much more sound foundation than all other damage indicators, also that PARK-ANG index (3).
As explained in Figure 7, damage indicators (18) are defined by using the eigenvalues of $\mathbf{K}_{T}$ as state variables of a certain deformed structural situation. For evaluation, in each damage state these eigenvalues have to be solved from the eigenvalue problem

$$
\left[\mathbf{K}_{T}(\mathbf{V}, \mathbf{d})-\mathbf{\Lambda}\right] \cdot \boldsymbol{\Phi}_{\lambda}=\mathbf{0}
$$

Herein, $\boldsymbol{\Lambda}$ forms a $(m * m)$ diagonal matrix of all eigenvalues $\lambda_{i}$, the actual principal stiffness elements of the structure. $\Phi_{\lambda}$ assembles the rows of eigenvectors (eigenmode shapes) of $\mathbf{K}_{T}$. If we remember orthogonality of $\Phi_{\lambda}$, we find from (19) by left multiplication with $\Phi_{\lambda}^{T}$

$$
\boldsymbol{\Phi}_{\lambda}^{T} \boldsymbol{\Phi}_{\lambda}=\mathbf{I} \Longrightarrow \boldsymbol{\Lambda}=\overline{\mathbf{K}}_{T}=\boldsymbol{\Phi}_{\lambda}^{T} \mathbf{K}_{T}(\mathbf{V}, \mathbf{d}) \boldsymbol{\Phi}_{\lambda},
$$

that the matrix $\boldsymbol{\Lambda}$ describes physically an energy. Because $\mathbf{K}_{T}$ is defined in the tangential subspace of the increments $\{\delta \mathbf{V}, \delta \mathbf{P}\}, \boldsymbol{\Lambda}$ can be interpreted as virtually dissipated energy at the point of $\mathbf{K}_{T}$.

Classical nonlinear structural dynamics offers a highly efficient extension of (17), (19) for practical damage detection, in numerical simulation as well as in physical testing. Therefore we superpose upon an actual nonlinearly deformed, quasistatic state of response $(\mathbf{P}, \mathbf{V}, \mathbf{d})$ of the considered structure an infinite set of infinitesimally small harmonic vibrations

$$
\delta \mathbf{P}=\mathbf{0}:\left(\mathbf{K}_{T}-\omega_{i}^{2} \mathbf{M}\right) \cdot \delta \mathbf{V}=\mathbf{0}, \quad i=1, \ldots m
$$




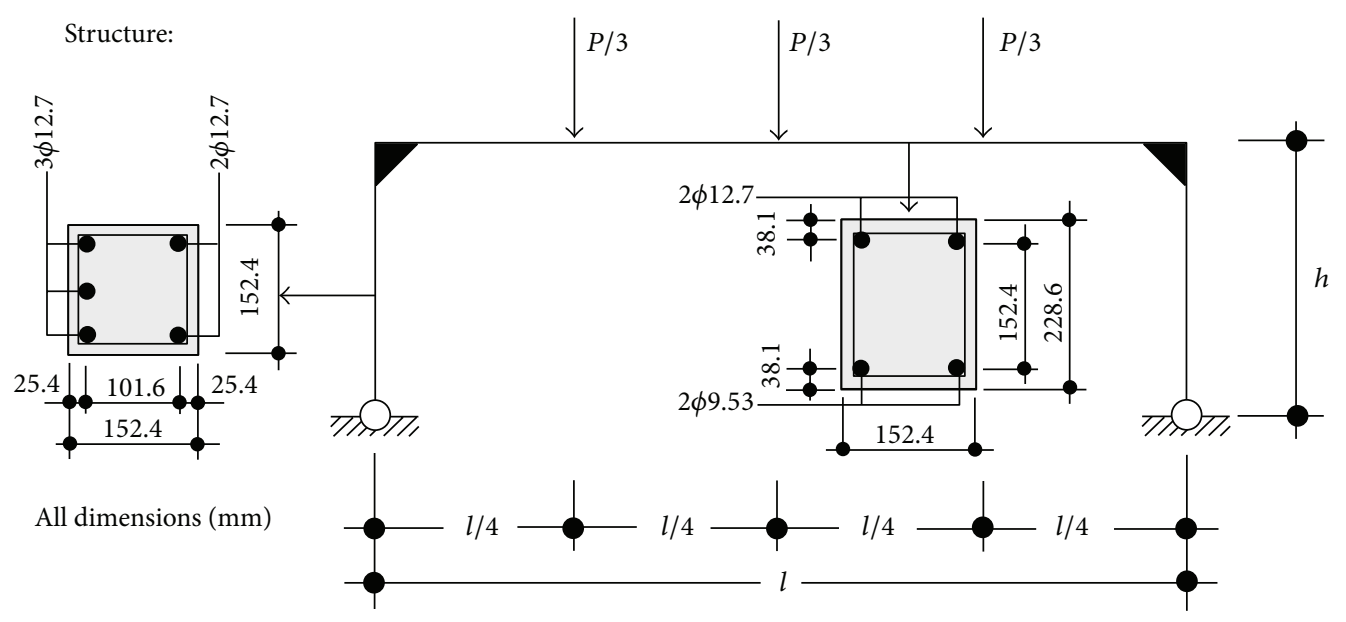

Dimensions and materials: $l=5486.4 \mathrm{~mm}(18 \mathrm{ft}), h=1828.8 \mathrm{~mm}(6 \mathrm{ft})$

Concrete: $f_{\mathrm{cm}}=40.82 \mathrm{MPa}$

Reinforcement: $E_{S}=209 \mathrm{GPa} \phi 9.53: f_{y} / f_{\mathrm{su}}=472.3 / 837.0 \mathrm{MPa}, \varepsilon_{\mathrm{su}}=0.077$

$$
\phi 12.7: f_{y} / f_{\mathrm{su}}=455.5 / 702.6 \mathrm{MPa}, \varepsilon_{\mathrm{su}}=0.110
$$

FIGURE 8: Dimensions and material specifications of RC test frame.

Studying the (squared) frequency spectrum $\omega_{i}^{2}$ as a solution of the eigenvalue problem (21), the latter delivers for zeros of $\mathbf{K}_{T}$ the statement $\omega_{i}^{2}=0$, identical with the quasistatic failure condition det $\mathbf{K}_{T}=0$. So for $\mathbf{M}$ distributed evenly over the structure, eigenfrequencies $\omega_{i}$ are likewise well suited as the eigenvalues $\lambda_{i}$ in (17) for damage detection:

$$
\left[\mathbf{K}_{T}(\mathbf{V}, \mathbf{d})-\mathbf{\Omega M}\right] \cdot \boldsymbol{\Phi}_{\omega}=\mathbf{0} .
$$

Herein $\boldsymbol{\Omega}$ forms a $(m * m)$ diagonal matrix with the (squared) frequency spectrum $\omega_{i}^{2}$ on its main diagonal. The $(m * m)$ square matrix $\Phi_{\omega}$ collects the rows of all $m$ vibration mode shapes. From (21) we derive by left-hand multiplication with $\Phi_{\omega}^{T}$

$$
\boldsymbol{\Phi}_{\omega}^{T} \mathbf{M} \boldsymbol{\Phi}_{\omega}=\mathbf{I} \Longrightarrow \boldsymbol{\Omega}=\operatorname{diag}\left\{\omega_{i}^{2}\right\}=\boldsymbol{\Phi}_{\omega}^{T} \mathbf{K}_{T}(\mathbf{V}, \mathbf{d}) \boldsymbol{\Phi}_{\omega}
$$

interpreting $\omega_{i}^{2}$ as virtually dissipating energies of the modal forces $\left(\mathbf{K}_{T} \boldsymbol{\Phi}_{\omega}\right)$ along the virtual vibration mode shapes $\boldsymbol{\Phi}_{\omega}^{T}$. An analogous energy interpretation has just been drawn from (20). The use of eigenfrequencies $\omega_{i}$ for evaluation of damage indicators compared to eigenvalues $\lambda_{i}$ is advantageous, because of generally less problems in setting up (22) compared to (19). This substitution holds true, because both matrices $\Lambda$ and $\boldsymbol{\Omega}$ can be related to each other by:

$$
\Lambda=\boldsymbol{\Phi}_{\omega}^{T} \mathbf{M} \boldsymbol{\Phi}_{\lambda} \boldsymbol{\Omega} \boldsymbol{\Phi}_{\lambda}^{-1} \boldsymbol{\Phi}_{\omega} .
$$

In the literature, also more complex functions of the eigenvalues $\lambda_{i}$ are recommended for formation of damage indicators [6] due to the definition on top of Figure 7.

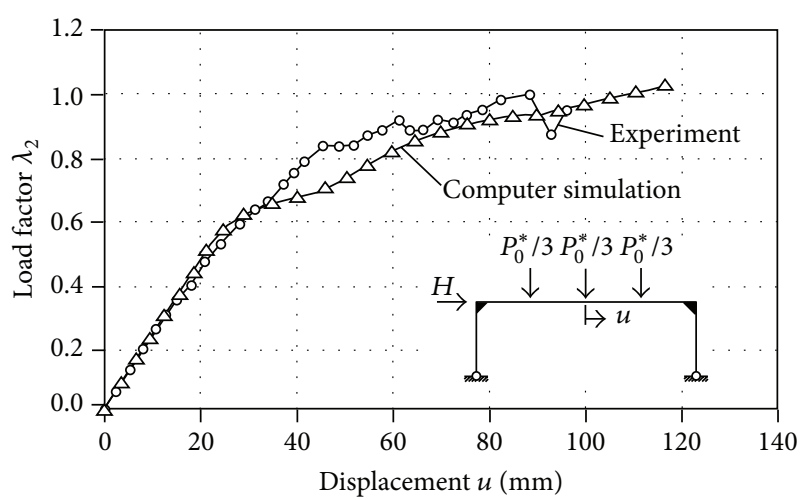

FIGURE 9: Load-deflection diagram for horizontal loading $H$.

\section{Example 1: Damage Formation in RC Test Frame}

We now demonstrate the application of the derived damage concept by hand of a RC test frame, the testing of which had been published in detail 40 years ago [22]. The test frame as well as all necessary geometrical and material data of this experiment is reprinted in Figure 8.

The 2-hinge test frame carries three equal loads $P / 3$ in the quarter-points of the girder, and one horizontal load $H$ on the girder due to Figure 9. For an anti-seismic design, the evaluation of $H$ from a seismic design spectrum due to the steps in Chapter 4 is straight forward. In one of the experiments [22], the test frame first was predamaged by a total vertical loading up to $P_{0}^{*}=26.5 \mathrm{kN}$. Maintaining this load then the horizontal (pushover) load $H$ as sketched in Figure 9 has been applied and increased until failure of the structure at $H=14.2 \mathrm{kN}$. 


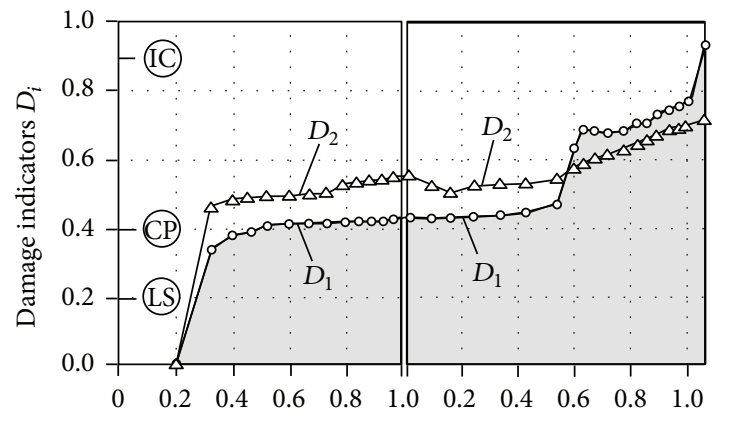

Load factor $\lambda_{1}$, Load factor $\lambda_{1}^{*} P_{0}$, Load factor $\lambda_{2}$, Load $P_{0}+\lambda_{2} H$

(a)

(b)

FIGURE 10: Damage indicators for vertical (a) load and additional horizontal (b) load $H$.

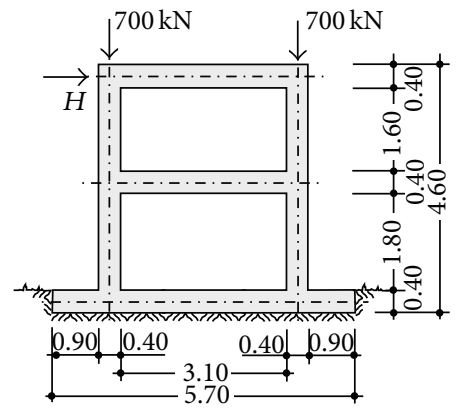

Test frame

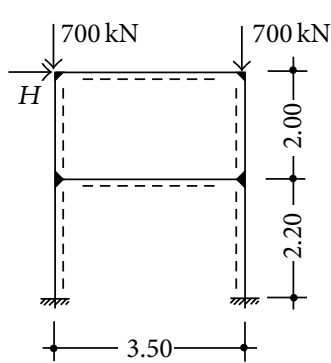

Mechanical model

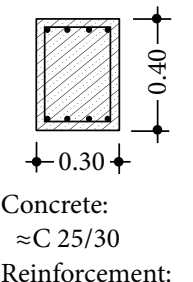

$2 \times 4 \phi 20$ BSt 500

Cross-section

FIGURE 11: 2-story RC test frame.

The load-deformation diagram $\mathbf{P}(\mathbf{V}, \mathbf{d})$ of the second loading phase, the application of the horizontal force, in Figure 9 plots $H$ against the horizontal girder displacement $u$. Therein both the experimentally monitored and the computed deformations are plotted, the latter evaluated by the described multilevel-simulation concept in a complicated nonlinear analysis. Both curves show sufficient correspondence for encouragement of the damage simulation.

Those results are depicted in Figure 10 for both damage variables $D_{1}, D_{2}$, based on the eigenvalues $\lambda_{1}, \lambda_{2}$. The computed damage variables $D_{1}, D_{2}$ are plotted there in the left part of the Figure as functions of the vertical loading, then in the right part as functions of the horizontal (pushover) load $H$. Details of the complicated nonlinear load-deformation process can be observed much clearer by hand of the damage evolution on this latter Figure. Obviously, $D_{1}$ describes the structure's path to final failure, although its effect under vertical loading is less than $D_{2}$. At the point of the extreme load $H$, structural equilibrium could be iterated for the last time, terminating the final damage evolution in Figure 10(b) somewhere between 0.90 and 1.00 , close to the theoretical unit value.

\section{Example 2: Damage Formation of a 2-Story RC Frame}

A 2-story RC frame will serve as second example, the testing of which had been described in [23]. Figure 11 depicts all necessary dimensions, with equal cross-sections of both beams and columns. In this example, the frame model applied in the nonlinear simulation is a simple beam/column structure. The concrete strength corresponds to C25/30, and the reinforcement, 4 bars of $20 \mathrm{~mm}$ diameter on each side, has the European steel quality BSt 500 .

To demonstrate the general applicability of the derived damage concept, this example will use an extremely simple, straightforward design analysis, without any sophisticated nonlinear simulation techniques. It will again show only the nonlinear pushover analysis and omit any seismic evaluation of the applied horizontal load $H$. The analysis is carried out as in simple design practice by the use of a linear elastic frame program and successive load application on the structure. At each structural position reaching the yield moment of the beam model, a plastic hinge is introduced, and the further analysis is carried out with this reduced redundant structure. The stiffness reductions of the progressively cracking RC members, on their way to reinforcement yielding, are considered by iterations. As a foundation of this modeling, Figure 12 shows the $M-\kappa$ diagrams, purely based on the (monotonic) prescriptions in [3].

The gained load-displacement curve is compared in Figure 13 with the global backbone curve of the cyclic swell test [23] demonstrating excellent agreement. The damage evolution on Figure 14 uses eigenfrequencies, evaluated for each different structural systems of each load step. Because 


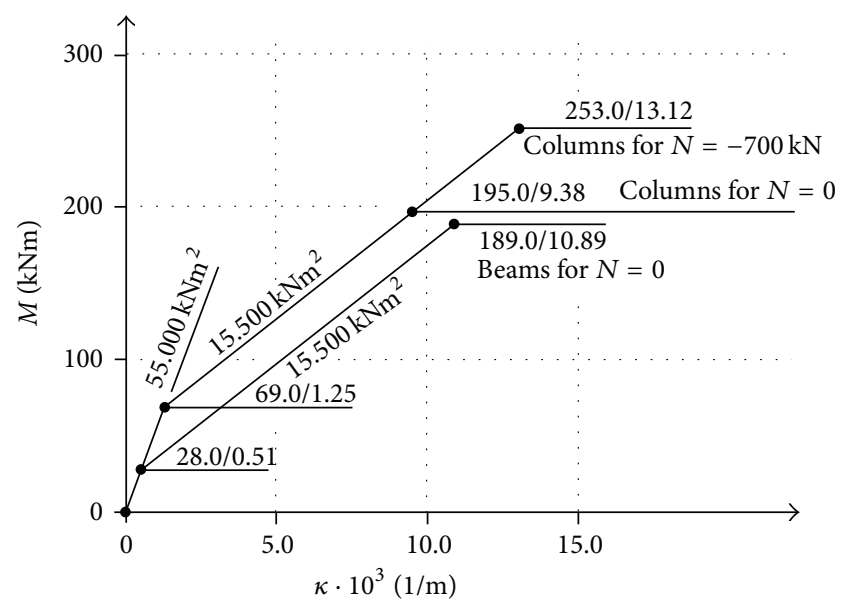

FiguRE 12: $M-\kappa$ diagrams for all sections of the test frame.

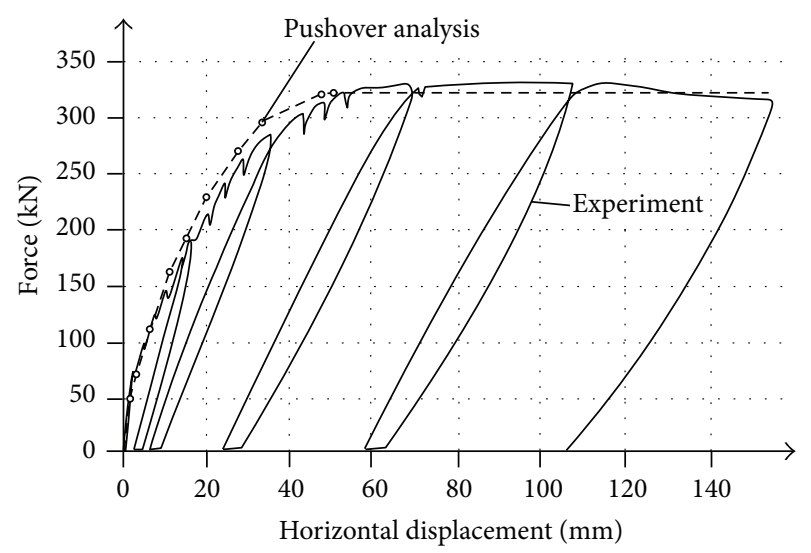

FIGURE 13: Load-deflection diagram of test frame under horizontal load $H$.

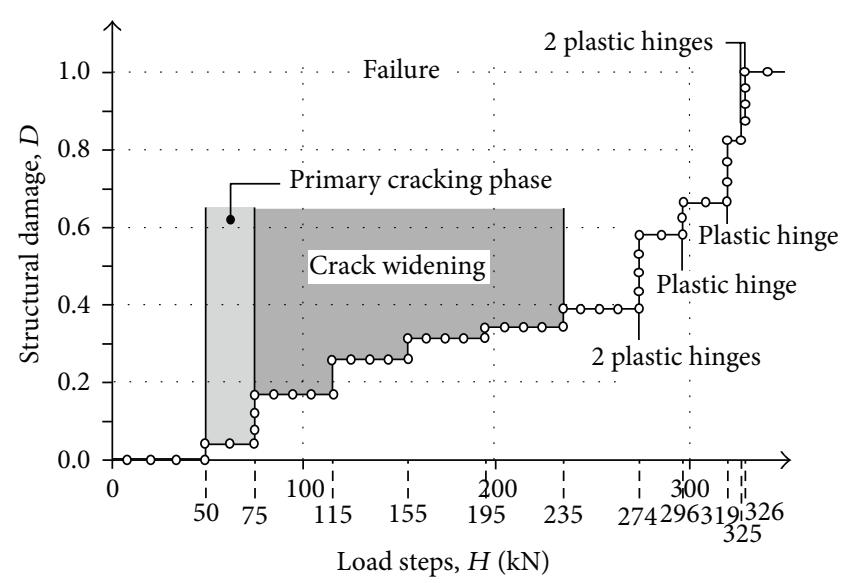

FIGURE 14: Damage indicators (eigenfrequencies) of test frame under load $H$.

of the applied plastic hinge model, the analysis is straightforward by standard software. Looking at Figure 14, we can clearly distinguish the brief uncracked phase with $D \equiv 0$ from the further primary cracking and crack-widening phases. Close to failure at $D=1$, we observe the expected rapidly successive formation of plastic hinges, transforming the originally resistant structure into a kinematic chain.

\section{Summary}

In the center of present seismic design codes stands the safe protection of human lives, but with growing building investments, installation, and equipment also viewpoints of property protection increase. As proposed by FEMA Standards [2], such extension requires the prosecution of a structure's damage path by damage indicators, which are able to scale the arising structural damage.

The present manuscript derives such a damage indicator, based on dissipated energies of virtual mode shapes/modal forces, and is connected to the structural response by the tangential stiffness matrix $\mathbf{K}_{T}$ during the nonlinear solution process. Thereby it adopts the quasistatic seismic safety concepts of most design codes and proposes for damage evaluation the seismic load-path evolution of the tangential stiffness $\mathbf{K}_{T}$ as well known from pushover analyses. Using the evolution of its eigenvalues or natural frequencies, the paper derives damage indicators, which fulfill all requirements from [2] and are-as accompanying data fields of design analysesrelatively easy to determine. The present examples should be further extended, for instance, to new structural types, in order to get more general experience with the applicability of the proposed damage measures.

Seismic damage is known as a low-cycle fatigue process, which is approximated in this manuscript in a quasistatic manner. Similar damage indicators have been successfully applied to the analysis of longtime structural deterioration $[9,19]$ and also to high-cycle fatigue structural phenomena [24].

\section{Conflict of Interests}

The authors declare that there is no conflict of interests regarding the publication of this paper.

\section{References}

[1] EC 8, Design Provisions for Earthquake Resistance of Structures, CEN European Committee for Standardization, Brussels, Belgium, 1994.

[2] Federal Emergency Management Agency, "Guidelines for the seismic rehabilitation of buildings," FEMA 273, Federal Emergency Management Agency, Washington DC, USA, 1997.

[3] EC 2, Design of Concrete Structures, Part 1: General Rules and Rules for Buildings, CEN European Committee for Standardization, Brussels, Belgium, 1991.

[4] A. J. Kappos and G. Panagopoulos, "Performance-based seismic design of 3D RC buildings using inelastic static and dynamic analysis procedures," ISET Journal of Earthquake Technology, vol. 41, pp. 141-158, 2004.

[5] W. B. Krätzig and K. Meskouris, "Assessment of seismic structural vulnerability as a low-cycle fatigue process," in Proceedings of the 11th European Conference on Earthquake Engineering, P. Bisch et al., Ed., pp. 161-178, A.A. Balkema, Rotterdam, The Netherlands, 1999. 
[6] SEAOC, "Vision 2000-performance based seismic design of buildings," Committee Report, Structural Engineers Association of California, Sacramento, Calif, USA, 1995.

[7] Y. Park and A. H.-S. Ang, "Mechanistic seismic damage model for reinforced concrete," Journal of Structural Engineering, vol. 111, no. 4, pp. 722-739, 1985.

[8] W. B. Krätzig, "Multi-level modeling technique for elasto-plastic structural responses," in Proceedings of the 5th International Conference Computational Plasticity, D. R. J. Owen et al., Ed., vol. 1, pp. 457-468, CIMNE, Barcelona, Spain, 1997.

[9] W. B. Krätzig and Y. S. Petryna, "Structural damage and life-time estimates by nonlinear FE simulation," Engineering Structures, vol. 27, no. 12, pp. 1726-1740, 2005.

[10] W. B. Krätzig, "Damage indicators for estimates of seismic vulnerability," in Innovations in Computational Structures Technologies, B. H. V. Topping et al., Ed., pp. 111-132, Saxe-Coburg Publications, Stirlingshire, UK, 2006.

[11] H. Krawinkler and G. D. P. K. Seneviratna, "Pros and cons of a pushover analysis of seismic performance evaluation," Engineering Structures, vol. 20, no. 4-6, pp. 452-464, 1998.

[12] B. Gupta and S. K. Kunnath, "Adaptive spectra-based pushover procedure for seismic evaluation of structures," Earthquake Spectra, vol. 16, no. 2, pp. 367-392, 2000.

[13] V. Kilar and P. Fajfar, "Simplified push-over analysis of building structures," in Proceedings of the 11th World Conference on Earthquake Engineering, pp. 59-66, Acapulco, Mexico, 1996.

[14] A. K. Chopra, Dynamics of Structures, Theory and Applications to Earthquake Engineering, Prentice Hall, Upper Saddle River, NJ, USA, 2001.

[15] L. Petti, L. Marino, M. De Iuliis, and G. Giannatasio, “The role of modeling in the push-over analysis of existing framed structures," in Proceedings of the (COMPDYN '07), M. Papadrakakis et al., Ed., Civil Engineering Software, Rethymno, Greece, June 2007.

[16] E. DiPasquale and A. S. Cakmak, "Detection and assessment of seismic structural damage," National Center for Research on Earthquake Engineering Research, Technical Report NCEER87-0015, State University of New York, Buffalo, NY, USA, 1987.

[17] I. F. Meyer, W. B. Krätzig, and F. Stangenberg, "Damage prediction in reinforced concrete frames under seismic action," EEE-European Earthquake Engineering, vol. 3, pp. 9-15, 1988.

[18] A. Ötes, "Zur werkstoffgerechten Berechnung der Erdbebenbeanspruchung in Stahlbetontragwerken," Tech. Rep. 25, Institute f. Reinforced Concrete, TH Darmstadt, 1985.

[19] W. B. Krätzig and Y. S. Petryna, "Fundamental tools for structural damage indication and lifetime management," in Proceedings of the 2nd International Conference on LifetimeOriented Design Concepts (ICLODC '04), F. Stangenberg et al., Ed., SFB 398, Ruhr-University, Bochum, Germany, 2004.

[20] Y. S. Petryna, "Structural degradation, reliability and lifetime simulations of civil engineering structures," in Proceedings of the 9th International Conference on Structural Safety and Reliability (ICOSSAR'05), Rome, Italy, G. Augusti, G. I. Schueller, and M. Ciampoli, Eds., Millpress, Rotterdam, The Netherlands, 2005.

[21] Y. S. Petryna and W. B. Krätzig, "Compliance-based structural damage measure and its sensitivity to uncertainties," Computers and Structures, vol. 83, no. 14, pp. 1113-1133, 2005.

[22] G. C. Ernst, G. M. Smith, A. R. Riveland, and D. N. Pierce, "Basic reinforced concrete frame performance under vertical and horizontal loads," American Concrete Institute Journal, vol. 70, no. 4, pp. 261-269, 1973.
[23] F. J. Vecchio and M. B. Emara, "Shear deformations in reinforced concrete frames," ACI Structural Journal, vol. 89, no. 1, pp. 46-56, 1992.

[24] Y. S. Petryna, D. Pfanner, F. Stangenberg, and W. B. Krätzig, "Reliability of reinforced concrete structures under fatigue," Reliability Engineering and System Safety, vol. 77, no. 3, pp. 253261, 2002. 


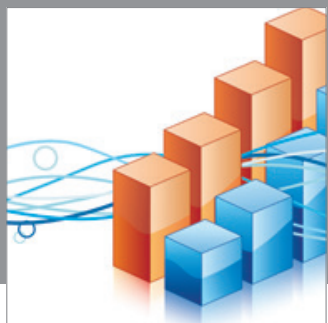

Advances in

Operations Research

mansans

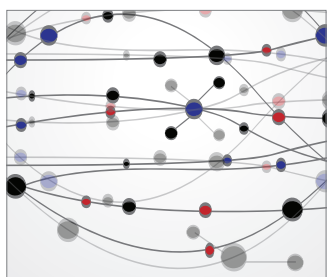

The Scientific World Journal
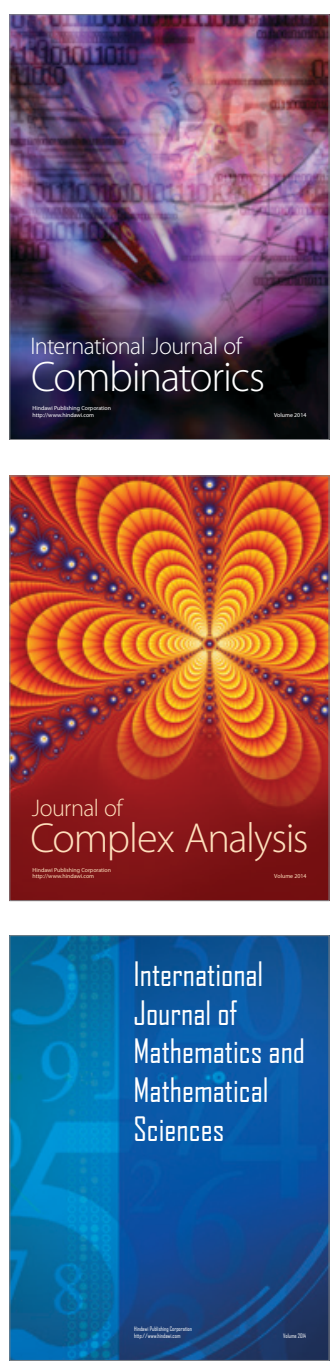
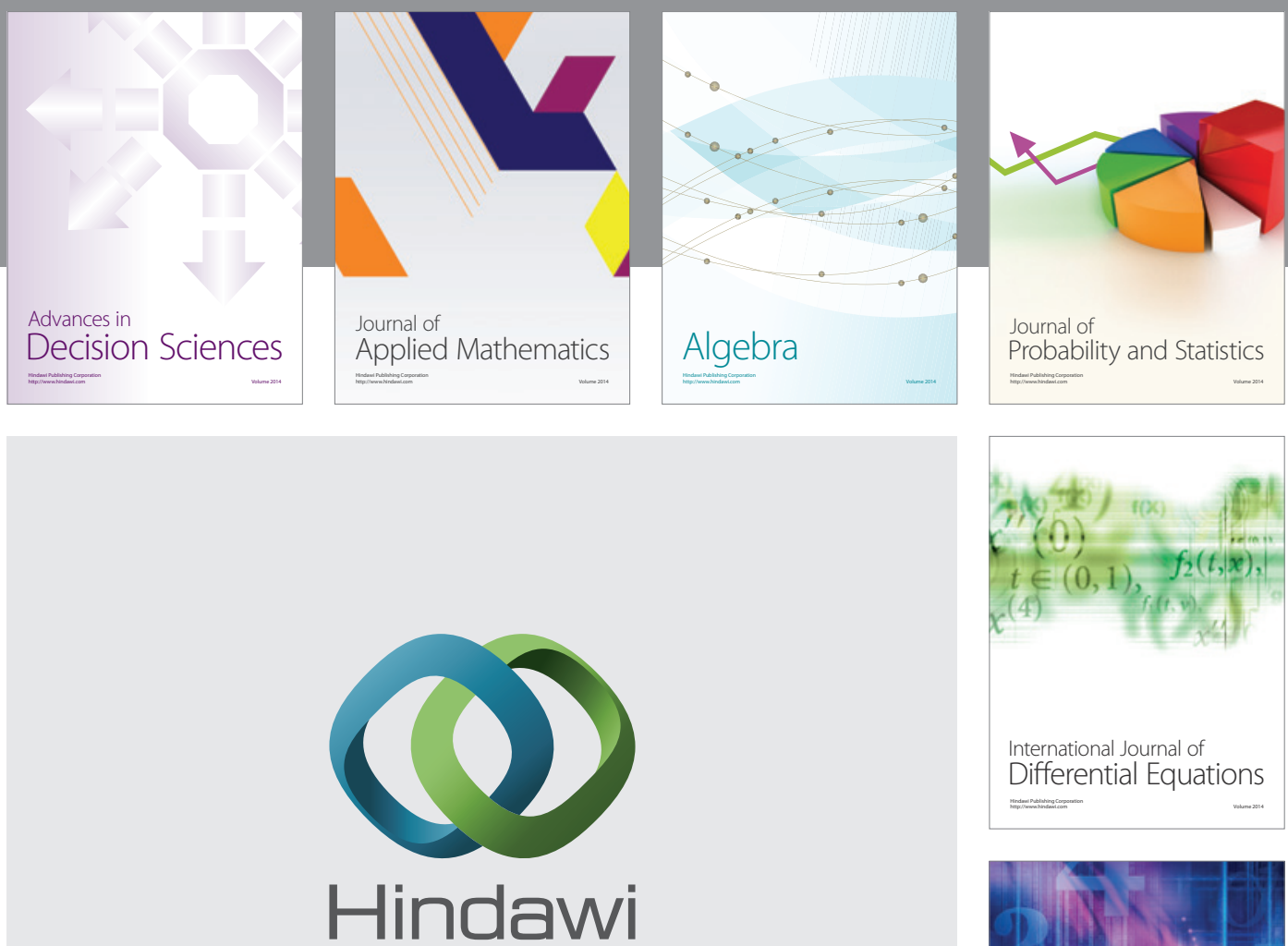

Submit your manuscripts at http://www.hindawi.com
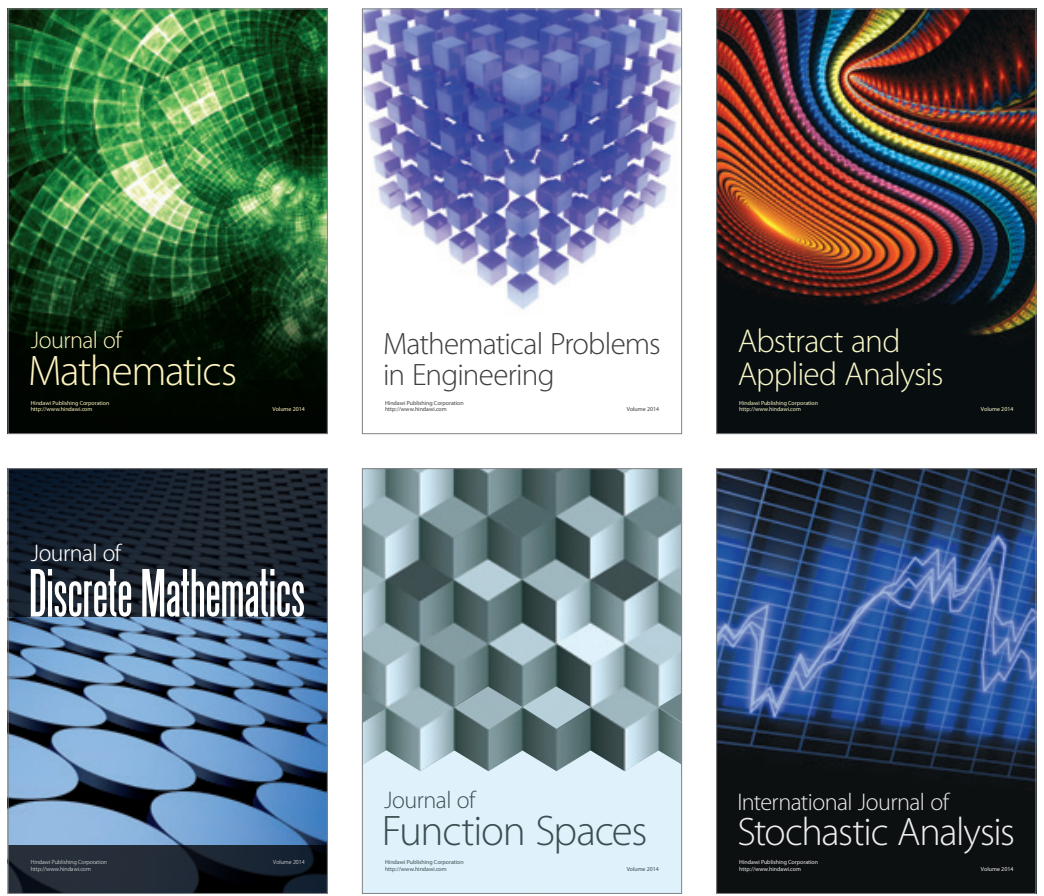

Journal of

Function Spaces

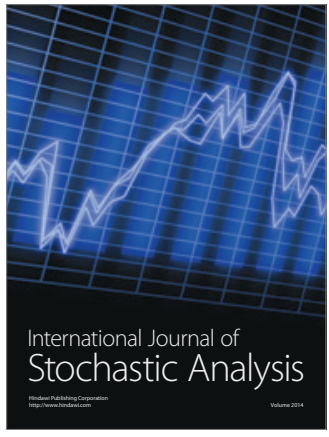

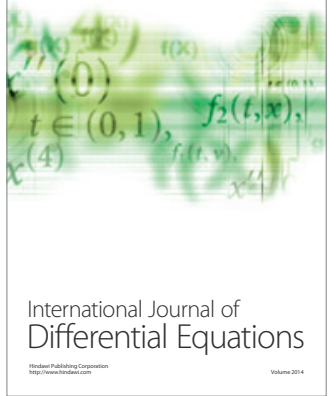
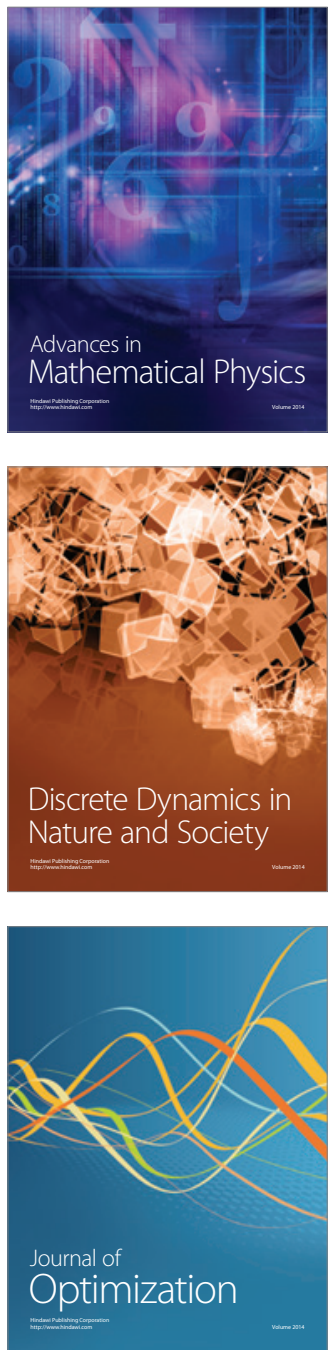